\title{
Interpersonal Communication: A Stress Reducing Remedy
}

\author{
Mr. Jefin Mathews, Mrs. Sheljy Shajan
}

\begin{abstract}
Stress is becoming a major physiological and psychological concern to each individual of the world. Along with the modern families where the scope of mutual interaction gradually diminishing, negative effects of stress exacerbates. Caring touch and free communication lack in families nowadays. Even though the burden of stress is heavy, the simplest technique of interpersonal communication is sufficient to relieve it. Communication with the significant person is the simple and 'an effective' technique to keep away the ill effects of stress.
\end{abstract}

Index Terms- stress, burn out, interpersonal communication.

\section{INTRODUCTION}

World is striving every moment to climb the pinnacle of achievement. As we consider this decade's eye on A STEP BEYOND THE EXCELLENCE, every single person in this universe is trying to kick on achievement. There will not be any fraction of seconds in this world that someone achieves and someone stresses. Greater the achievement, bigger the scope of stress and being stressed has become a common phenomenon.

\section{A. Stress- A World Wide Concern}

Stress has become a major concern all over the globe. It transforms even the simplest activity of an individual to a difficult task and hinder the desirable outcome. It is strong enough also to shake the foundation of a concrete relationship. People of all age groups are exposed to different stressors at one or different point of life. The depleted adaptive energy can be a source of suicidal thoughts. By considering this impending risk, World Health Day Campaign considered their theme in 2017 as 'Depression, Let's talk[1]

Awareness of the problem is the prime step in any problem-solving approach. The agent of a stress can be physical, psychological and situational. Stressor can be any life event or daily hurdles or physical, psychological or social circumstances. Reactions can occur in two directions 1) adaptive 2) maladaptive. Adaptive responses, keep up the self-esteem of the individual intact. Maladaptive responses, disrupt the self-esteem of the individual and make him vulnerable. The coping capacity varies in each individual. Hence the reactions precipitate by a stressor may also vary. The symptoms of anxiety and depression develop in response to stress. So, stress can be defined as an individual's specific

Mr. Jefin Mathews, Max Health Care, Patparganj

Mrs. Sheljy Shajan, St. Stephan's Hospital College of Nursing. reactions to a stressor in their own particular way.

Giving an appropriate definition to Stress was a troublesome task for the psychologists and still working on it. But more reliably stress can be viewed as "an individual's reaction to any change that requires an adjustment or response which can be physical, mental or emotional" [2]

\section{Burnout as A Major Stressor}

In today's technologically advanced world, burnout is the main stressor of the target population. It is when, one cannot achieve his goal and his efforts toward it become vain. Unresolved conflicts clump together and leads to an endangering unhealthy stress. But not all stress can be with negative productivity. In certain situations, it mobilises efforts and enhance accomplishment. But beyond a certain point it becomes harmful and causing damage to our health, performance and relationships.

\section{General adaptation syndrome (GAS)}

Stress can function as a major contributor in many serious diseases like coronary heart disease, cancer, lung ailments and suicides which are known $s$ to be the prime causes of death in the United States. So, it is significant to discuss about GAS here. This is the reaction when we face a stressor. Hans Selye detailed this reaction in three distinct stages.

In the first stage of alarm reaction, body perceives the stressor and alarm self and initiate "fight or flight syndrome".

In the second stage of resistance "The individual uses the physiological responses of the first stage as a defence in an attempt to adapt to the stressor. If adaptation occurs, the third stage is prevented or delayed. Physiological symptoms may disappear".

Prolonged exposure to stressors make the individual experiencing depleted adaptive energy, result in an exhaustion stage. 'Diseases of adaptation (e.g., headaches, mental disorders, coronary artery disease, ulcers and colitis) may occur. Without intervention, exhaustion deepens and, in some cases, even death" [2]

\section{B. Communication in Stress Management}

It is impossible to eradicate stress in our daily life. But adaptive coping of stress is inevitable for an individual to master, reduce or tolerate it. Perception of the stressor by an individual should be realistic. Assessment of skills, resources and knowledge that an individual possess has to be reviewed for enabling him to cope up with the stressor.

Seventy years after independence, the state of health care is pathetic as evidenced by minimal access to underprivileged and vulnerable population. Stress need to be intervened on 
immediate basis as it affects the performance of employees. Health care system have responded to the need for services that facilitate stress reduction strategies for individuals and groups. In fact, stress management become professional as well as economic target now. Health care settings have identified the need for services that impart stress management information to individuals [3]

Interpersonal communication is a process of sharing information between two persons. To share, acceptance is required from both sides. For generating acceptance, trust must be developed primarily, followed by a confiding relationship. So interpersonal communication is not merely a communication, it is more than a communication.

Active listening is the supremely needed component in communication. Sometimes just talking the problem out with an individual who is empathetic is sufficient to interrupt escalation of stress response. Being interested in a communication verbally and non-verbally can create a climate in which an individual can develop a trustworthy relationship, internalising his own energy sources and resolving the stress effectively.

There are research evidences supporting the significance of interpersonal communication. Investigators suggested that much of psychosocial problems can be minimized by effective communication. This study was conducted regarding stress, coping strategies and quality life of institutionalized and non-institutionalized elderly in Kottayam District, Kerala and aims to assess the stress level and coping strategies adopted by the elderly in different life situation. [4].

The presence of a healthy support system significantly predicts the ability of an individual to cope with the stress. Presence of a supporting relationship can help the people to forget undesirable events to live confidently. Presence of a hand to hold and an ear to hear in any situation will increase a person's energy to progress.

\section{CONCLUSION}

The hectic scheduled life style of a modern family will play a platform of stress and related physiological and psychological conflicts. But the essence of intimate communication between the family members can carry the energy to vanish it away to a great extent. Parents, the primary care givers and their mentors must encourage and facilitate the children with this golden technique so that the family can become more fruitful to themselves and the society too.

\section{REFERENCES}

[1] Depression: Let's talk. (2018). Retrieved from http://www.who.int/campaigns/world-health-day/2017/en/

[2] H., L. (1957). The Stress of Life. Hans Selye, M.D. New York, McGraw-Hill Book Company, Inc. 1956. \$5.95. The Journal of Bone \& Joint Surgery, 39(2), 479. 10.2106/00004623-195739020-00034

[3] Townsend, M. (2010). Psychiatric mental health nursing (pp. 2-8). Philadelphia: F.A. Davis.

[4] Anu mathew, M., George, L., \& Paniyadi, N. (2009). Indian Journal of Gerontology

\section{AUTHOR I}

MR JEFIN MATHEWS

Education-Bachelor Of Nursing

Designation-Nursing Supervisor

Membership- Registered Nurse

Achievements- Acls Provider, Diabetic Nurse Educator

\section{AUTHOR-2}

MRS SHELJY SHAJAN

Education-Msc.N(Psychiatric Nursing)

Designation-Lecturer In Nursing

Publication-Original Research Article Published In Ijhsr

Membership-Registered Nurse.

Achievements-Examiner, Paper Setter, Coordinator Of Academic Activities 